\title{
CRITICAL AORTIC STENOSIS IN THE NEONATE: A MULTI-INSTITUTIONAL STUDY OF MANAGEMENT, OUTCOMES, AND RISK FACTORS
}

Gary K. Lofland, MD ${ }^{\mathrm{a}}$

Brian W. McCrindle, MD ${ }^{\mathrm{b}}$

William G. Williams, MD $^{c}$

Eugene H. Blackstone, $\mathrm{MD}^{\mathrm{d}}$

Christo I. Tchervenkov, MD

Rekwan Sittiwangkul, MD

Richard A. Jonas, MD ${ }^{\mathrm{f}}$

Congenital Heart Surgeons Society
Objectives: We sought to determine factors that would predict whether a biventricular repair or Norwood procedure pathway would give the best survival in neonates with critical aortic stenosis.

Methods: Survival and risk factors were determined with parametric timedependent event analysis for patients undergoing either the Norwood procedure or biventricular repair, and predicted optimal pathway and survival benefit were derived from multivariable linear regression.

Results: From 1994 to 2000, 320 neonates with critical left ventricular outflow obstruction were entered into a prospective multi-institutional study. Patients who died without intervention $(n=19)$ and those with primary cardiac transplantation $(n=6)$ were excluded. An initial intended biventricular repair pathway was indicated in 116 patients, with survival of $70 \%$ at 5 years. An initial Norwood procedure was performed in 179 patients, with survival of $60 \%$ at 5 years. Using predictions from separate multivariable hazard models for survival with each of the 2 pathways, we determined predicted optimal pathway and survival benefit for each patient. Significant independent factors associated with greater survival benefit for the Norwood procedure versus biventricular repair included younger age at entry, lower z-score of the aortic valve and left ventricular length, higher grade of endocardial fibroelastosis, absence of important tricuspid regurgitation, and larger ascending aorta. Predicted survival benefit favored the Norwood procedure in $50 \%$ of patients who had biventricular repair, and it favored biventricular repair in $20 \%$ of patients who had the Norwood procedure.

Conclusions: Morphologic and functional factors can be used to predict optimal pathway and survival benefit in neonates with critical left ventricular outflow obstruction. (J Thorac Cardiovasc Surg 2001;121:10-27)
From the Section of Cardiac Surgery, ${ }^{a}$ Children's Mercy Hospital, Kansas City, Mo; Division of Cardiology, ${ }^{\mathrm{b}}$ The Hospital for Sick Children, Toronto, Ontario, Canada; Division of Cardiovascular Surgery, ${ }^{c}$ The Hospital for Sick Children, Toronto, Ontario, Canada; Department of Thoracic and Cardiovascular Surgery, ${ }^{\mathrm{d}}$ Cleveland Clinical Foundation, Cleveland, Ohio; Division of Cardiovascular Surgery, e Montreal Children's Hospital, Montreal, Quebec, Canada; and Department of Cardiac Surgery, ${ }^{f}$ The Children's Hospital, Boston, Mass.

Financial support for this project and the Congenital Heart Surgeons Society Data Center is provided by the members of the Society and by a grant from the Hospital for Sick Children, Toronto, Ontario, Canada.

Read at the Eightieth Annual Meeting of The American Association for Thoracic Surgery, Toronto, Ontario, Canada, April 30-May 3, 2000.

Received for publication May 4, 2000; revisions requested June 22, 2000; revisions received Aug 17, 2000; accepted for publication Aug 25, 2000.

Address for reprints: Gary K. Lofland, MD, Section of Cardiac Surgery, The Children's Mercy Hospital, 2401 Gillham Rd, Kansas City, MO 64108 (E-mail: glofland@cmh.edu).

Copyright $\odot 2001$ by The American Association for Thoracic Surgery 0022-5223/2001 $\$ 35.00+0 \quad \mathbf{1 2 / 6 / 1 1 1 2 0 7}$

doi: $10.1067 / \mathrm{mtc} .2001 .111207$
Drevious studies from the Congenital Heart Surgeons Society (CHSS) have examined in detail risk factors and survival patterns in patients with aortic atresia, in patients with interrupted aortic arch,, ${ }^{1,2}$ and in patients with coarctation of the aorta. All of these diseases are characterized by significant obstruction to left ventricular outflow, significant interference with systemic arterial perfusion, or both. In addition to these patients, there exists a complex group of patients without aortic atresia but with critical left ventricular outflow obstruction, with patency of the aortic valve and either systemic arterial flow depending on patency of the ductus arteriosus or with markedly depressed left ventricular function at presentation.

Considerable anatomic and morphologic variability exists within this patient collection. Aortic valves may be morphologically normal but miniature, anatomically small and dysplastic, or of adequate size for the patient's body surface area but morphologically dysplastic and stenotic. Any of these scenarios may result 
in severe left ventricular outflow tract obstruction or critical aortic stenosis.

Of equal importance in this patient population is the status of the mitral valve. The mitral valve may be small but morphologically normal or dysplastic and stenotic.

Other considerations include adequacy of left ventricular size and function, presence of an atrial septal defect, presence of a ventricular septal defect, and presence of coarctation of the aorta.

Patients with critical aortic stenosis have a wide range of therapeutic options, allowing for considerable controversy in their management. Decision-making is further complicated by the need to rapidly decide on a course of therapy. In the absence of specific therapy, closure of the ductus arteriosus results in death from congestive heart failure, systemic hypoperfusion, or coronary insufficiency.

A study of outcomes in a large group of neonates with left ventricular outflow tract abnormalities resulting in critical aortic stenosis could be of value in the care of these critically ill neonates. A multi-institutional study was undertaken to determine the management and outcomes of these patients and to identify risk factors for early survival.

We sought to determine the demographic, functional, and morphologic factors that would predict whether a biventricular repair or Norwood single-ventricle palliation pathway would give the best survival in neonates with critical left ventricular outflow obstruction.

\section{Patients and methods}

Between January 1994 and February 2000, 320 neonates (aged $<30$ days) with critical aortic stenosis (critical left ventricular outflow tract obstruction) were entered into a prospective study. Twenty-four institutions contributed patients to this study. Participation in this project and submission of patient information were voluntary and confidential. To the best of our knowledge, these case totals represent all of the patients presenting to each of the institutes participating in this study. All patients meeting entry criteria were enrolled.

Study population. Patients were eligible for entry into the study if they were admitted to a participating CHSS institution, had the appropriate cardiac diagnosis, and were selected for a procedure addressed at the left ventricular outflow obstruction (including cardiac transplantation) within 30 days of birth. All consecutive patients were prospectively entered into the study between January 1994 and February 2000. Critical left ventricular outflow obstruction was defined as the presence of moderately or severely reduced left ventricular function at entry (time of initial admission to CHSS institution) or the presence of systemic perfusion dependent on right ventricular output via a patent arterial duct. All patients had to have important left ventricular outflow obstruction or hypoplasia with concordant atrioventricular and ventriculoarterial connections, with echocardiographic, angiographic, or surgical demonstration of patency of the aortic valve. Patients with large ventricular septal defects or associated cardiac anomalies judged to be of worse prognostic significance than their left ventricular obstructive lesions were excluded.

Data collection. Investigators were requested to submit copies of medical records, including imaging reports, procedure reports, and hospital discharge summaries. Records of subsequent clinical assessments, hospital admissions, and procedures were also submitted. In addition, the physician, family, or guardian of each patient not known to have died was contacted each year since the beginning of the study, and vital status and intervening problems and procedures were ascertained. The most recent follow-up for patients enrolled in the earlier years of the study was conducted between May and September 1999. Follow-up was $100 \%$ complete with no patients being lost to follow-up. As this is an ongoing study, enrollment of patients continues. For purposes of statistical analysis, only patients enrolled before February 2000 were included. Patients enrolled after February 2000 will be included in subsequent studies. Confidentiality of patient information was maintained.

Cardiac function and morphology. Quantitative and qualitative data of cardiac structure and function were abstracted from reports of echocardiograms, angiograms, operations, and autopsies to confirm patient eligibility. Functional and morphologic predictors of outcomes were derived from the initial echocardiogram performed at presentation, and data were abstracted. The format for echocardiographic data tabulation is illustrated in Appendix A. Given variability in the standardization and comprehensiveness of submitted echocardiographic reports, we defined an echocardiographic measurement protocol for multiple left heart obstructive or hypoplastic lesions. Initial (before any important intervention) echocardiogram videotape recordings were requested from contributing institutions. The submitted recordings were then reviewed and standardized measurements made by a single experienced pediatric echocardiographer blinded to subsequent management and outcome of the patient. From an initial study population of 323 neonates, 214 initial echocardiogram recordings were received and underwent independent review. From the review, 3 patients were identified and excluded from further analysis due to demonstrated lack of patency of the aortic valve (aortic atresia). Data were abstracted from detailed echocardiography reports regarding an additional 40 patients for whom a recording was not submitted for review. For the remaining patients, functional and morphologic data were abstracted from reports of cardiac catheterization, surgery, and autopsy. Echocardiographic morphologic measurements were standardized to body surface area as z-scores on the basis of published normative data. ${ }^{3}$ Dimensions were also normalized by indexing to body surface area.

Management. All initial and subsequent procedures were noted. On the basis of the first procedure performed to address the left ventricular outflow obstruction, patients were grouped according to their initial designation by their institution as being on either a 2-ventricle or biventricular repair pathway or a single-ventricle palliation or primary cardiac transplantation pathway. Initial biventricular repair proce- 
Table I. Selected patient characteristics

\begin{tabular}{|c|c|c|c|c|c|c|c|}
\hline \multirow[b]{3}{*}{ Variable } & \multicolumn{6}{|c|}{ Initial intended pathway } & \multirow{3}{*}{$\mathrm{P}$ value } \\
\hline & \multicolumn{3}{|c|}{ Biventricular repair $(n=116)$} & \multicolumn{3}{|c|}{ Norwood procedure $(n=179)$} & \\
\hline & $\mathrm{n}$ & $\mathrm{m}$ & Value & $\mathrm{n}$ & $\mathrm{m}$ & Value & \\
\hline Median (range) age at entry (d) & 116 & 0 & $2(0-29)$ & 179 & 0 & $1(0-30)$ & $<.015$ \\
\hline Sex, female/male & 116 & 0 & $15: 101$ & 178 & 1 & $60: 118$ & $<.001$ \\
\hline Associated cardiac anomalies & 116 & 0 & $7(6 \%)$ & 179 & 0 & $11(6 \%)$ & .97 \\
\hline Persistent left SVC & 116 & 0 & $4(3 \%)$ & 179 & 0 & $12(7 \%)$ & .30 \\
\hline Genetic or anomaly syndrome & 116 & 0 & $2(2 \%)$ & 179 & 0 & $7(4 \%)$ & .50 \\
\hline Noncardiac anomaly & 116 & 0 & $5(4 \%)$ & 179 & 0 & $11(6 \%)$ & .61 \\
\hline \multicolumn{8}{|l|}{ Morphology and function } \\
\hline Echocardiogram independently reviewed & 116 & 0 & $82(71 \%)$ & 179 & 0 & $116(65 \%)$ & .30 \\
\hline \multicolumn{8}{|l|}{ Mean $(\mathrm{SD}) \mathrm{z}$-score: } \\
\hline Tricuspid valve diameter & 83 & 33 & $-1.38(2.26)$ & 119 & 60 & $-0.83(2.17)$ & .09 \\
\hline Mitral valve diameter (4-chamber view) & 86 & 30 & $-2.22(2.82)$ & 121 & 58 & $-6.38(2.91)$ & $<.001$ \\
\hline Mitral valve diameter (long-axis view) & 82 & 34 & $-1.20(1.99)$ & 118 & 61 & $-5.33(2.70)$ & $<.001$ \\
\hline LV endocardial length (4-chamber view) & 83 & 33 & $-0.84(2.26)$ & 112 & 67 & $-5.63(3.23)$ & $<.001$ \\
\hline Aortic valve anulus (long-axis view) & 101 & 15 & $-3.69(2.40)$ & 146 & 33 & $-8.25(3.75)$ & $<.001$ \\
\hline Aortic valve at sinuses (long-axis view) & 83 & 33 & $-2.51(2.30)$ & 119 & 60 & $-6.28(3.50)$ & $<.001$ \\
\hline $\begin{array}{l}\text { Aorta at sinotubular junction } \\
\text { (long-axis view) }\end{array}$ & 81 & 35 & $-0.41(2.25)$ & 116 & 63 & $-4.44(3.33)$ & $<.001$ \\
\hline ASD & 94 & 22 & $16(17 \%)$ & 136 & 43 & $47(35 \%)$ & .004 \\
\hline Mean $(\mathrm{SD})$ ratio of RA/LA area & 80 & 36 & $0.93(0.34)$ & 110 & 69 & $1.29(0.51)$ & $<.001$ \\
\hline VSD & 93 & 23 & $7(8 \%)$ & 133 & 46 & $31(23 \%)$ & .002 \\
\hline Moderate or large VSD & 93 & 23 & $5(5 \%)$ & 133 & 46 & $25(19 \%)$ & .004 \\
\hline Moderate or severe tricuspid regurgitation & 90 & 26 & $6(7 \%)$ & 129 & 50 & $10(8 \%)$ & .77 \\
\hline $\begin{array}{l}\text { Mean }(\mathrm{SD}) \text { ratio of mitral valve } \\
\text { area to total } \mathrm{AV} \text { valve area }\end{array}$ & 74 & 42 & $0.45(0.09)$ & 107 & 72 & $0.26(0.10)$ & $<.001$ \\
\hline Moderate or severe mitral regurgiation & 101 & 15 & $9(9 \%)$ & 126 & 53 & $3(2 \%)$ & .037 \\
\hline Moderate or severe mitral stenosis & 93 & 23 & $1(1 \%)$ & 130 & 49 & $20(16 \%)$ & $<.001$ \\
\hline Parachute mitral valve & 90 & 26 & $2(2 \%)$ & 123 & 56 & $13(11 \%)$ & .03 \\
\hline Grade of endocardial fibroelastosis & 90 & 26 & & 119 & 60 & & \\
\hline None & & & $47(52 \%)$ & & & $59(50 \%)$ & .54 \\
\hline Mitral valve papillary muscles only & & & $34(38 \%)$ & & & $42(35 \%)$ & \\
\hline + Some endocardial involvement & & & $7(8 \%)$ & & & $17(14 \%)$ & \\
\hline + Extensive endocardial involvement & & & $2(2 \%)$ & & & $1(1 \%)$ & \\
\hline Mean (SD) LV ejection fraction (\%) & 76 & 40 & $39(17)$ & 105 & 74 & $41(17)$ & .52 \\
\hline Moderate or severe subaortic obstruction & 99 & 17 & $6(6 \%)$ & 119 & 60 & $26(22 \%)$ & .001 \\
\hline Mean (SD) ascending aorta diameter (mm) & 88 & 28 & $8.1(2.2)$ & 147 & 32 & $5.6(1.8)$ & $<.001$ \\
\hline Presence of aortic coarctation & 104 & 12 & $11(11 \%)$ & 133 & 46 & $41(31 \%)$ & $<.001$ \\
\hline
\end{tabular}

$A S D$, Atrial septal defect; $A V$, atrioventricular; $L V$, left ventricular; $m$, number of missing values; $n$, number of non-missing values; $R A / L A$, right atrial/left atrial; $S D$, standard deviation; $S V C$, superior vena cava; VSD, ventricular septal defect.

dures included transcatheter balloon and surgical aortic valvotomy, primary aortic valve replacement, and the Yasui procedure (aortopulmonary anastomosis with Rastelli connection). Single-ventricle palliation consisted of the Norwood procedure and its modifications. Subsequent procedures, especially those related to left ventricular outflow obstruction, were also noted. In patients who crossed over to the alternate pathway after an initial procedure, the intended initial strategy was considered to have failed.

Data analysis. The goal of the analysis was directed to optimizing the initial decision for biventricular or non-biventricular repair pathway. All analyses were performed with SAS statistical software, version 7 (SAS Institute, Inc, Cary, NC). Data are described as frequencies, medians with ranges, and means with standard deviations as appropriate. In the case of missing data, the number of non-missing values is given for descriptive analyses. In all multivariable analyses, missing values for variables, particularly echocardiographic measurements, were managed as follows: In cases in which patient weight, height, or body surface area was not reported for the time of the echocardiogram report or recording, informative imputation was based on available patient characteristics using standard percentile growth charts, with the assumption that the patient's height and weight percentile would be concordant. A general missing value indicator variable was created for missing echocardiogram-recording review, and then the mean value of available information was substituted for missing values (noninformative imputation). In all multivariable analyses, the relevant missing value indicator variables were carried to adjust for the possibility that patients with a given value missing may be different in terms of characteristics or risk from those in whom the value is not missing. 


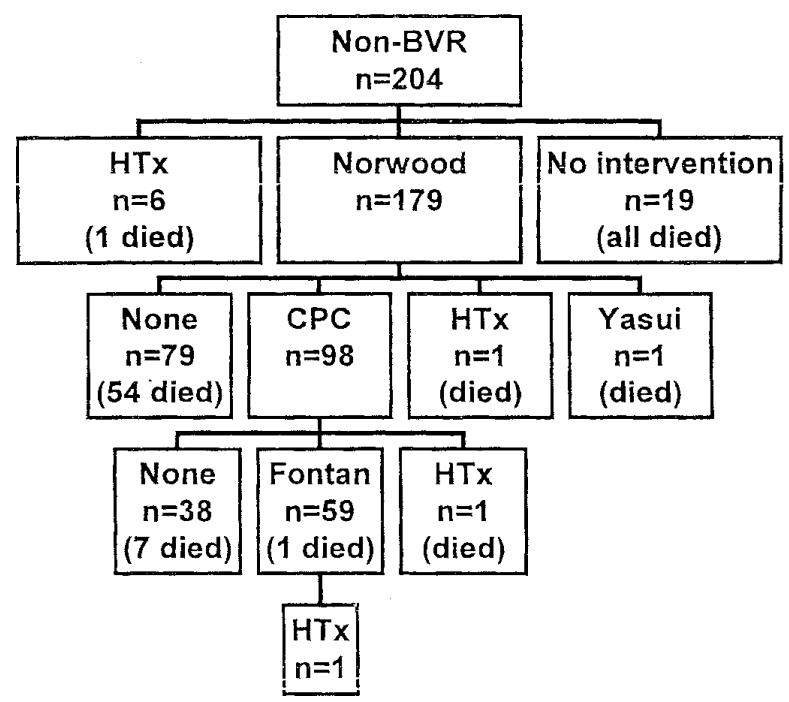

Fig 1. Subsequent procedures and mortality for patients who had an initial procedure indicating an intended nonbiventricular repair pathway or who died without having had a procedure to address the left ventricular outflow obstruction. BVR, Biventricular repair; CPC, cavopulmonary connection; HTx, heart transplantation; Yasui, creation of a Damus-Kaye-Stansel type connection with closure of a ventricular septal defect to incorporate the neoaorta to the left ventricle and a Rastelli-type connection from the right ventricle to the pulmonary arteries.

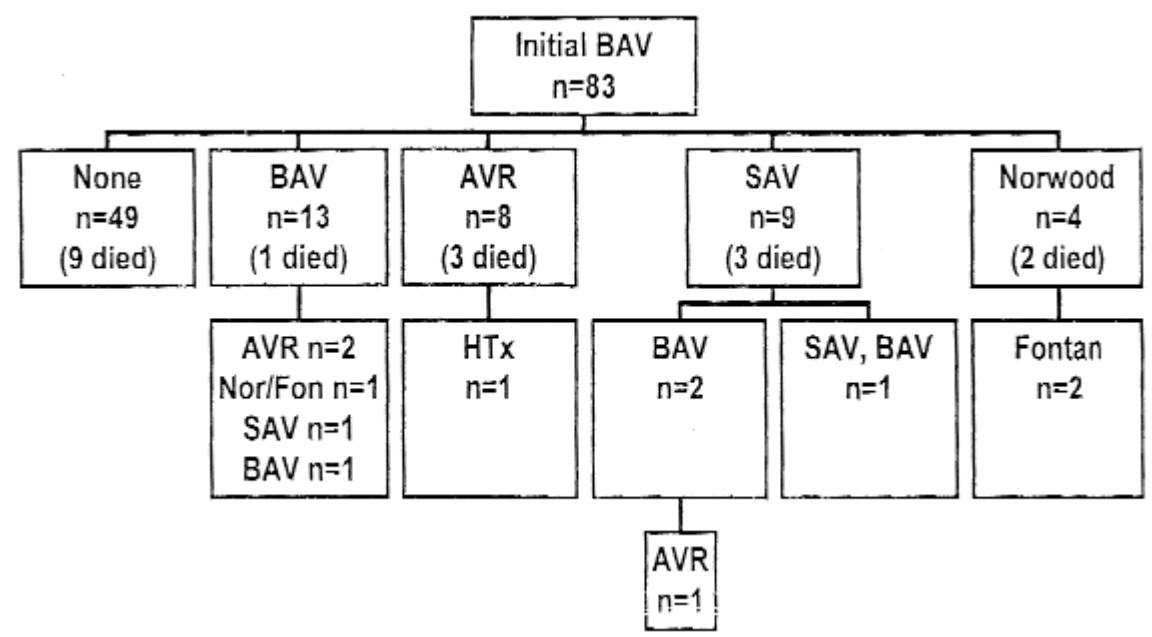

Fig 2. Subsequent procedures and mortality for patients who had an initial transcatheter balloon aortic valvotomy to address the left ventricular outflow obstruction. $A V R$, Aortic valve replacement; $B A V$, balloon aortic valvotomy; Fon, Fontan procedure; HTx, heart transplantation; Nor, Norwood procedure; SAV, surgical aortic valvotomy.

Factors associated with initial intended strategy. The management pathways of all patients were determined and described, including unintended crossover to alternative pathways. Patients who died before any procedure to address left ventricular outflow obstruction could be performed $(n=19)$ were excluded from further analysis. Independent demographic, functional, and morphologic factors associated with the initial intention for a biventricular versus a non-biventricular repair pathway were sought in multivariable logistic regression using the variables noted in Table I and Appendix A. For this analysis, ordinal and continuous variables were examined by decile analysis to determine possible transformations of scale needed to match the scale of the variable with the scale of the risk (calibration). Variables were screened by examining frequency tables, and those associated with 5 or fewer deaths were eliminated from consideration because of the risk of model overdetermination. Variables were entered into the model in a semidirected manner, with 


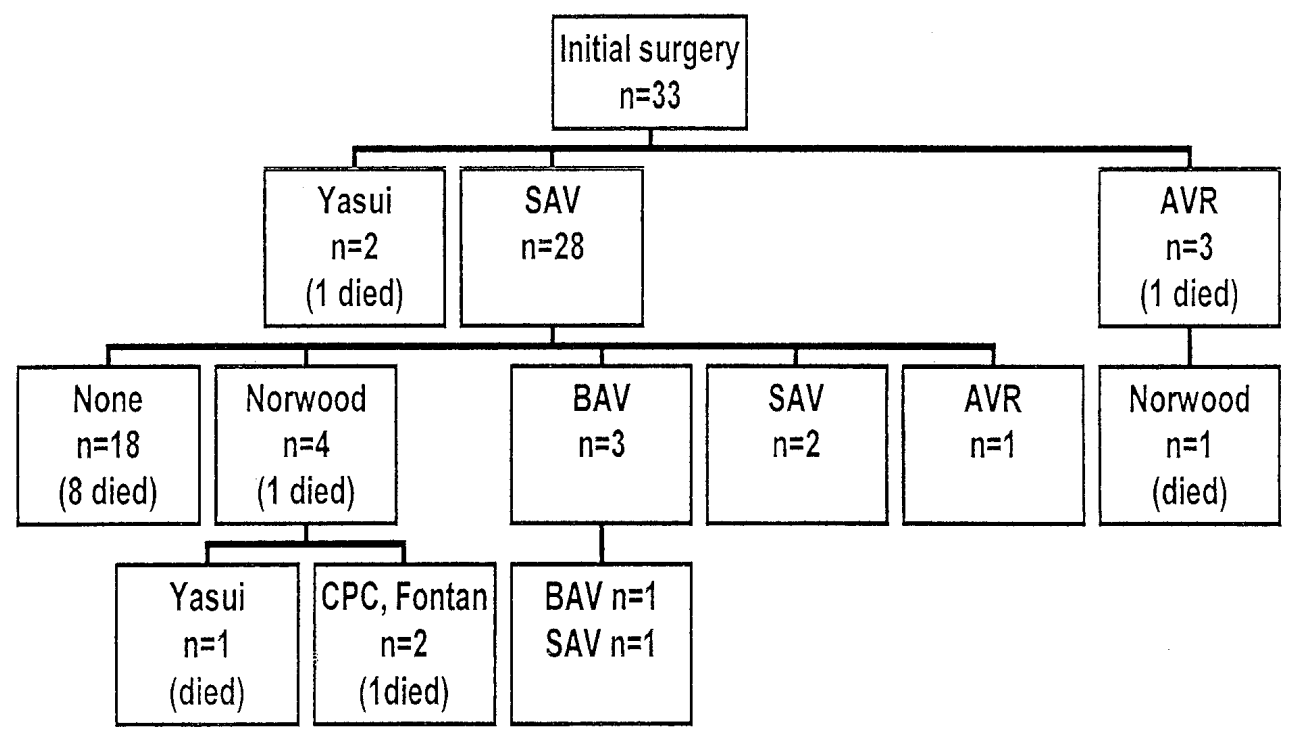

Fig 3. Subsequent procedures and mortality for patients who had an initial surgical procedure indicating an intended biventricular repair pathway. $A V R$, Aortic valve replacement; $B A V$, balloon aortic valvotomy; $C P C$, cavopulmonary connection; $S A V$, surgical aortic valvotomy; Yasui, creation of a Damus-Kaye-Stansel type connection with closure of a ventricular septal defect to incorporate the neoaorta to the left ventricle and a Rastelli-type connection from the right ventricle to the pulmonary arteries.

initial selection criteria for variable entry set at the $P \leq .15$ level of significance. Interaction terms were examined for additional entry into the final multivariable model.

Factors associated with time-related death. All-cause mortality was considered in this analysis. Non-risk-adjusted nonparametric estimates of time-related death were plotted as Kaplan-Meier estimates. Parametric estimates were obtained by modeling the hazard function, searching for multiple phases of risk and the characteristic equation of each phase. ${ }^{4}$ This analysis was initially performed for the entire study population and then separately for patients who had initial biventricular repair strategy and those who had an initial Norwood procedure. Patients who had primary cardiac transplantation ( $\mathrm{n}=$ 6) were excluded from this analysis due to small numbers and elimination of morphologic predictors. In this study, for all 3 analyses only a single early hazard phase was noted, so a single stream of concomitant variables was analyzed. The multivariable analysis was performed in a manner similar to that used for the multiple logistic regression analysis described above, with the same strategy for variable selection and retention in the models. Incremental risk factors for time-related deaths were determined separately for patients on an initial biventricular versus a Norwood procedure intention-to-treat pathway. The parameter estimates from the separate multivariable equations were then used in the subsequent analysis.

Prediction of survival benefit and optimal pathway. The optimal pathway and magnitude of survival benefit at 5 years after study entry were predicted for every patient in the 2 subgroups. This was accomplished by solving the multivariable hazard function equation twice for each patient, once for a Norwood procedure pathway and again for a biventricular repair pathway. The 2 values were then compared, with the difference representing the benefit in percent survival at 5 years for the optimal pathway for that patient on the basis of the characteristics as entered into the multivariable hazard function models.

To simplify prediction and to determine additional factors predictive of optimal pathway and survival benefit, we used multivariable linear regression analysis to model the difference in predicted percent survival for the Norwood procedure over the biventricular repair pathway. Model building strategy was similar to that described above. The final regression equation could then be solved for an individual patient's initial characteristics, with a positive number representing better predicted survival with the Norwood procedure, a negative number representing better predicted survival with a biventricular repair strategy, and the magnitude of the number representing the degree of predicted survival benefit.

\section{Results}

Study population and procedures. A total of 320 eligible neonates from 24 participating institutions were entered into the study. Of these, 19 patients either died before any intervention could be performed or had an intervention for a reason unrelated to left ventricular outflow tract obstruction and subsequently died. These patients were excluded from further analyses. Initial left ventricular outflow tract intervention indicated an intended non-biventricular repair pathway. Interventions included primary cardiac transplantation in 6 

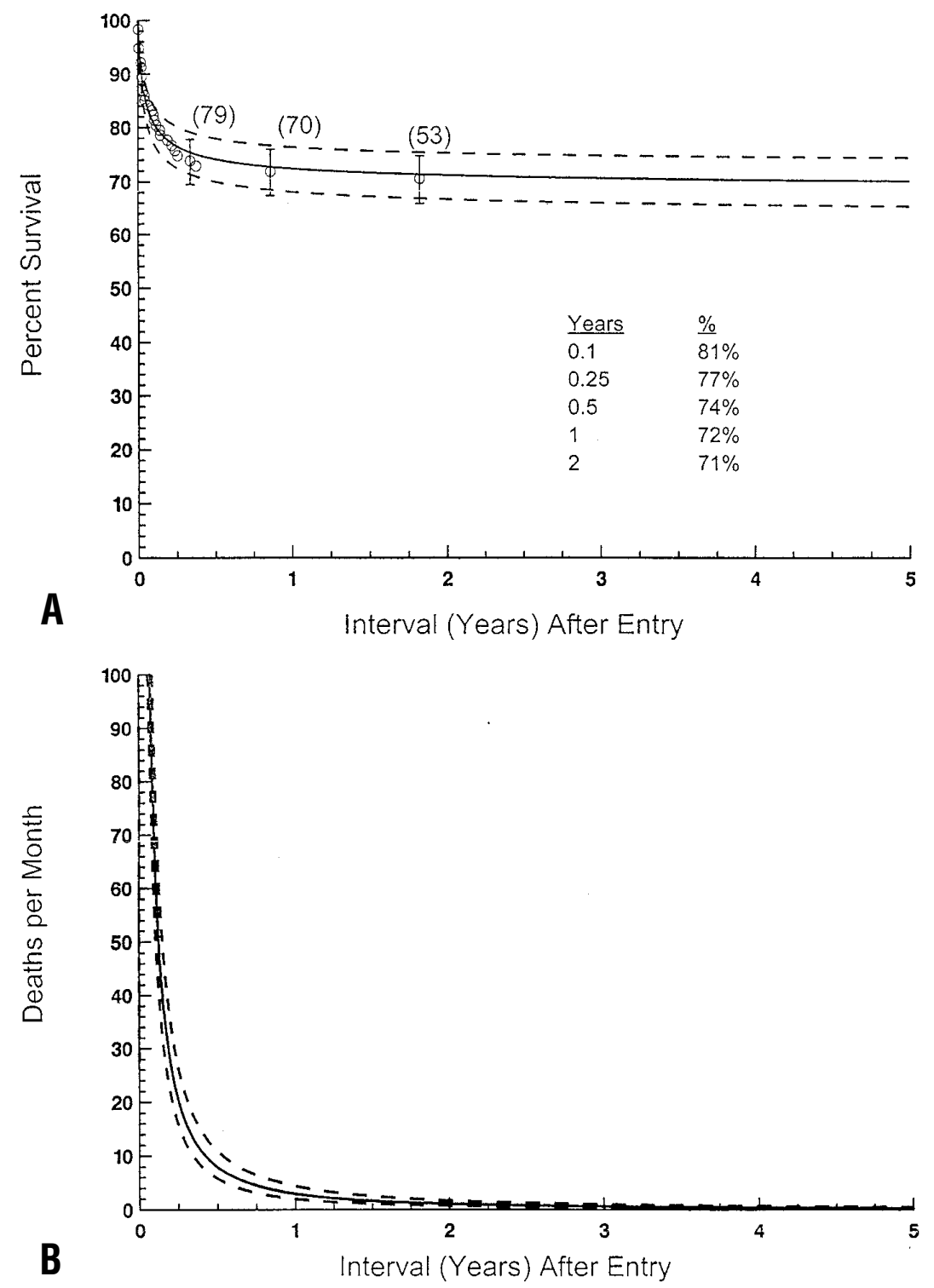

Fig 4. Survival after entry for patients who had an initial procedure indicating an intended biventricular repair pathway $(\mathrm{n}=116)$. The circles represent the Kaplan-Meier estimate for survival at each death, the solid lines represent the parametric determination of continuous point estimates, and the dashed lines enclose the $70 \%$ confidence interval. A, Percent survival; B, hazard function.

patients, with 1 subsequent death, and a Norwood procedure in 179 patients, with 64 subsequent deaths. An initial intended biventricular repair pathway was indicated in 116 patients, with 32 subsequent deaths. Initial and subsequent interventions for left ventricular outflow tract obstruction are shown in flow diagrams for patients on non-biventricular repair pathways (Fig 1) and for patients on an initial intended biventricular repair pathway who had either an initial transcatheter aortic balloon valvotomy (Fig 2) or an initial surgical procedure (Fig 3).
Characteristics by initial intended pathway. Given the small number of patients who had initial cardiac transplantation and the fact that cardiac replacement effectively neutralizes all initial functional and morphologic factors, these patients were excluded from all subsequent analysis, leaving only patients who had an initial Norwood procedure in the non-biventricular repair group. Demographic, functional, and morphologic characteristics of patients at initial entry are given in Table I, divided into 2 groups by initial intended pathway of either biventricular repair or Norwood procedure. 
Table II. Independent factors discriminating patients who had an initial intervention indicating a decision for a biventricular repair versus a Norwood procedure pathway for critical left ventricular outflow obstruction* (CHSS 1994-2000, $n=294$ )

\begin{tabular}{lccc}
\hline \multicolumn{1}{c}{ Variable } & Parameter estimate $\dagger($ SE) & Odds ratio (95\% CI) & P value \\
\hline Intercept & $1.750(0.776)$ & & \\
Higher z-score of aortic valve anulus diameter (per 1 SD increase) & $0.361(0.089)$ & $1.43(1.21,1.71)$ & \\
Higher initial echocardiographic peak instantaneous gradient & & & \\
$\quad$ across the LV outflow tract (per 10 mm Hg increase) & $0.537(0.116)$ & $1.71(1.36,2.15)$ & $<.001$ \\
Higher z-score of mitral valve anulus diameter (per 1 SD increase) & $0.559(0.136)$ & $1.75(1.34,2.28)$ & $<.001$ \\
Absence of aortic coarctation & $1.238(0.575)$ & $3.45(1.12,10.6)$ & .03 \\
Institution E & $1.380(0.625)$ & $3.97(1.17,13.5)$ & .03 \\
Institution K & $3.372(0.927)$ & $29.1(4.74,17.9)$ & $<.001$ \\
\hline
\end{tabular}

$C I$, Confidence interval; $L V$, left ventricular; $S D$, standard deviation; $S E$, standard error. Hosmer and Lemeshow goodness-of-fit test, $P=.44$.

*Excludes 19 patients who died with no intervention and 6 patients who had primary cardiac transplantation.

$\dagger$ Adjusted for missing information for peak instantaneous LV outflow tract gradient.

Table III. Incremental risk factors for time-related death for patients who had an initial procedure indicating an intended biventricular repair pathway

\begin{tabular}{lcc}
\hline \multicolumn{1}{c}{ Variable } & Parameter estimate* $(S E)$ & P value \\
\hline Higher grade of endocardial fibroelastosis $\dagger$ & $0.532(0.234)$ & .02 \\
Lower z-score of aortic valve diameter at the level of the sinuses of Valsalva & $0.360(0.109)$ & $<.001$ \\
Younger age at entry & $1.488(0.529)$ & .005 \\
\hline
\end{tabular}

*For a single early hazard phase; adjusted for missing information for z-score of the aortic valve at the level of the sinuses of Valsalva.

$\dagger$ Endocardial fibroelastosis was graded subjectively by the echocardiographic appearance of left ventricular endocardial brightness and thickening as follows: $0=$ none; 1 = involvement of papillary muscles only; 2 = papillary muscle with some endocardial surface involvement; $3=$ extensive endocardial surface involvement. $\ddagger$ Entered after inverse transformation.

Multivariable logistic regression analysis was used to determine independent factors associated with the initial intended decision to pursue a biventricular versus a Norwood procedure pathway. Independent factors discriminating an initial decision in favor of a biventricular repair pathway are shown in Table II and include a higher z-score of the aortic valve anulus diameter, a higher echocardiographic peak instantaneous gradient across the left ventricular outflow tract, a higher z-score of the mitral valve anulus diameter, the absence of an aortic coarctation, and 2 institutions. After controlling for these factors, no other variable met criteria for entry into the model. This equation discriminated the 2 groups with a great deal of accuracy, with an area under the receiveroperating characteristic curve of $0.947(P<.001)$.

Survival with biventricular repair pathway. Survival for the 116 patients who had an initial intervention indicating a biventricular repair pathway is shown in Fig 4. Survival was $82 \%$ at 1 month after entry, $77 \%$ at 3 months, $72 \%$ at 1 year, $71 \%$ at 2 years, and $70 \%$ at 5 years. Incremental risk factors for time-related death after entry are shown in Table III and include a higher subjective echocardiographic grade of endocardial fibroelastosis, a lower z-score of the aortic valve diameter at the level of the sinuses of Valsalva, and a younger age at entry. The effects of each of these significant factors on time-related death are shown in Figs 5 to 7.

Because the echocardiographic appearance was a significant predictor of survival in this group of patients, we compared the echocardiographic grade of endocardial fibroelastosis as noted by the independent blinded echocardiogram review to the findings at autopsy in those patients who had died, regardless of pathway or procedures, using the same criteria for the grading. Of the 211 patients who had echocardiogram review, 69 died, 37 of whom had some endocardial fibroelastosis. Autopsy findings were available for only 23 of the deaths, and the agreement is shown in Table IV. In general, agreement was fair, with a weighted kappa statistic of 0.33 (95\% confidence interval, 0.07-0.59), although 2 patients with extensive endocardial fibroelastosis at autopsy were believed to have no endocardial fibroelastosis on the initial echocardiogram.

Survival with Norwood procedure pathway. Survival for the 179 patients who had an initial Norwood procedure is shown in Fig 8. Survival was $80 \%$ at 1 month after entry, $71 \%$ at 3 months, $64 \%$ at 1 year, $62 \%$ 


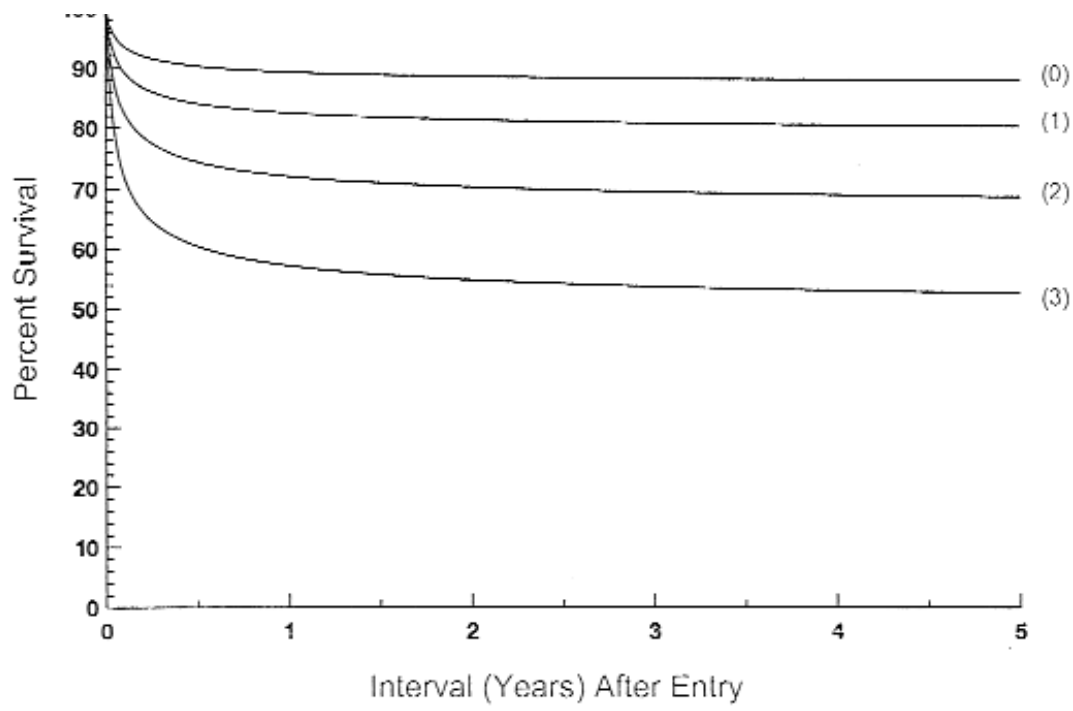

Fig 5. Risk-adjusted percent survival after entry predicted for a patient who had an initial procedure indicating an intended biventricular repair pathway $(n=116)$, stratified by the grade of endocardial fibroelastosis as noted on the initial echocardiogram. The patient age at entry was set at 2 days, and the z-score of the aortic valve at the level of the sinuses of Valsalva was set at -3 . Lines represent the parametric determination of continuous point estimates of survival according to grade: grade 0 , no endocardial fibroelastosis; grade 1, endocardial fibroelastosis on the mitral valve papillary muscles only; grade 2, endocardial fibroelastosis on the papillary muscles and some involvement of the endocardial surface of the left ventricle; and grade 3, extensive endocardial involvement.

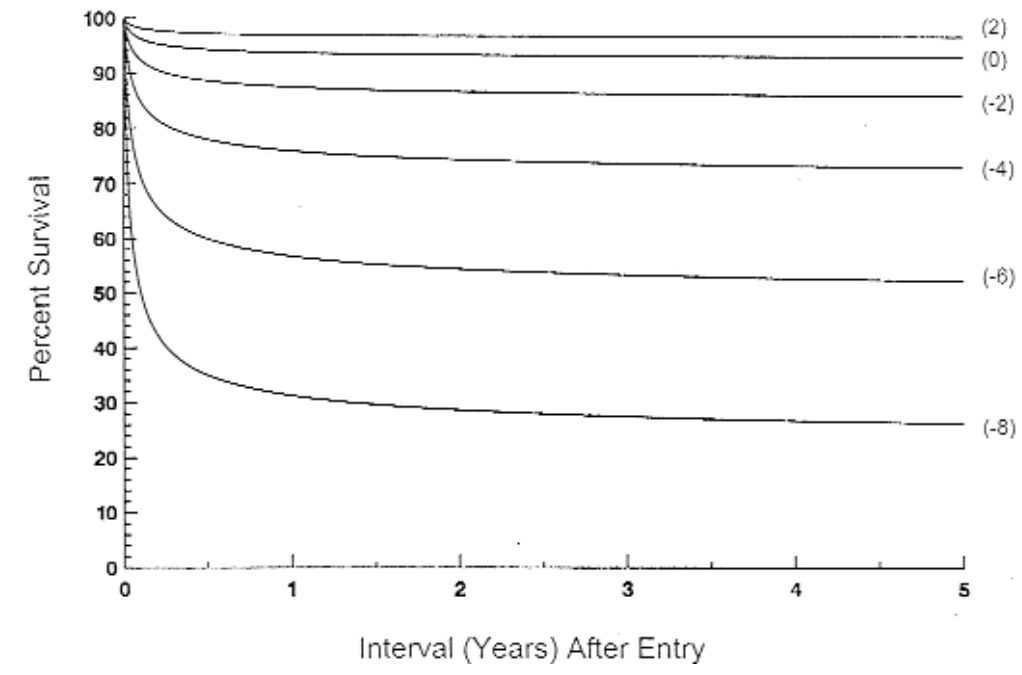

Fig 6. Risk-adjusted percent survival after entry predicted for a patient who had an initial procedure indicating an intended biventricular repair pathway $(n=116)$, stratified by values of the $\mathrm{z}$-score of the diameter of the aortic valve measured at the level of the sinuses of Valsalva on the initial echocardiogram. The patient age at entry was set at 2 days, and the grade of endocardial fibroelastosis as noted on the initial echocardiogram was set to 1 or involvement of the mitral valve papillary muscles only. Lines represent the parametric determination of continuous point estimates of survival.

at 2 years, and $60 \%$ at 5 years. Incremental risk factors for time-related death after entry are shown in Table V and include a lower diameter of the ascending aorta and the presence of moderate or severe tricuspid regurgita- tion. The effects of each of these significant factors on time-related death are shown in Figs 9 and 10.

Optimal pathway and survival benefit. By means of the separate hazard models for initial intended 


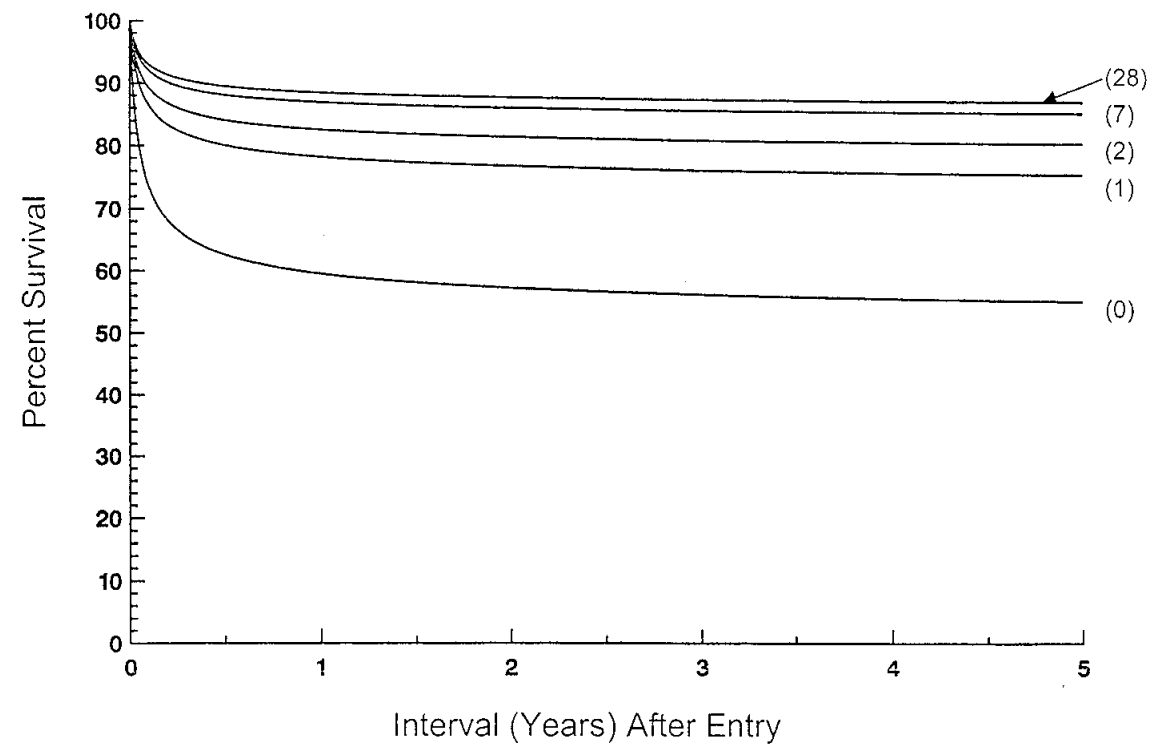

Fig 7. Risk-adjusted percent survival after entry predicted for a patient who had an initial procedure indicating an intended biventricular repair pathway $(n=116)$, stratified by the patient age at entry or first admission to a CHSS institution. The z-score of the aortic valve diameter measured at the level of the sinuses of Valsalva was set at -3 , and the grade of endocardial fibroelastosis was set at 1 or involvement of the mitral valve papillary muscles only. Lines represent the parametric determination of continuous point estimates of survival.

Table IV. Agreement between echocardiogram review and autopsy findings regarding grade of EFE

\begin{tabular}{lcccc}
\hline & \multicolumn{3}{c}{ Grade of EFE from autopsy } \\
\cline { 2 - 5 } & 0 & 1 & 2 & 3 \\
\hline Grade of EFE from echo review & & & 0 & 1 \\
0 & $7^{*}$ & 2 & 0 & 0 \\
1 & 6 & 0 & 0 & 4 \\
3 & 0 & 0 & 1 \\
\hline
\end{tabular}

echo, Echocardiogram; EFE, endocardial fibroelastosis. EFE was graded subjectively by the echocardiographic appearance of left ventricular endocardial brightness and thickening or by autopsy findings as follows: $0=$ none; $1=$ involvement of papillary muscles only; 2 = papillary muscle with some endocardial surface involvement; 3 = extensive endocardial surface involvement.

*Figures in the body of the table indicate the number of patients with each grade of EFE.

biventricular repair and Norwood procedure as applied to the combined data set, survival at 5 years after entry was predicted for each patient twice, once for the biventricular repair pathway and again for the Norwood procedure. The difference between the 2 numbers represented the predicted percent survival benefit for that patient on the basis of the characteristics for the optimal pathway. Independent factors from multiple linear regression analysis associated with this survival benefit are shown in Table VI. Independent factors associated with the difference in predicted survival favoring Norwood versus biventricular repair include a higher grade of endocardial fibroelastosis, lower z-score of the aortic valve at the level of the sinuses of Valsalva, younger age at entry, larger ascending aorta diameter, the absence of moderate or severe tricuspid regurgitation, and lower $\mathrm{z}$ score of the left ventricular length. These factors accounted for $89 \%$ of the variation in predicted survival benefit, indicating excellent fit of the model.

The regression equation can be solved for individual patients on the basis of their characteristics to give the predicted survival benefit. When this was performed for the patients in our study, 60 of the 116 patients $(52 \%)$ who had an initial procedure indicating a biventricular repair pathway would have had better predicted survival at 5 years after a Norwood procedure, with a mean increase in 5-year survival 

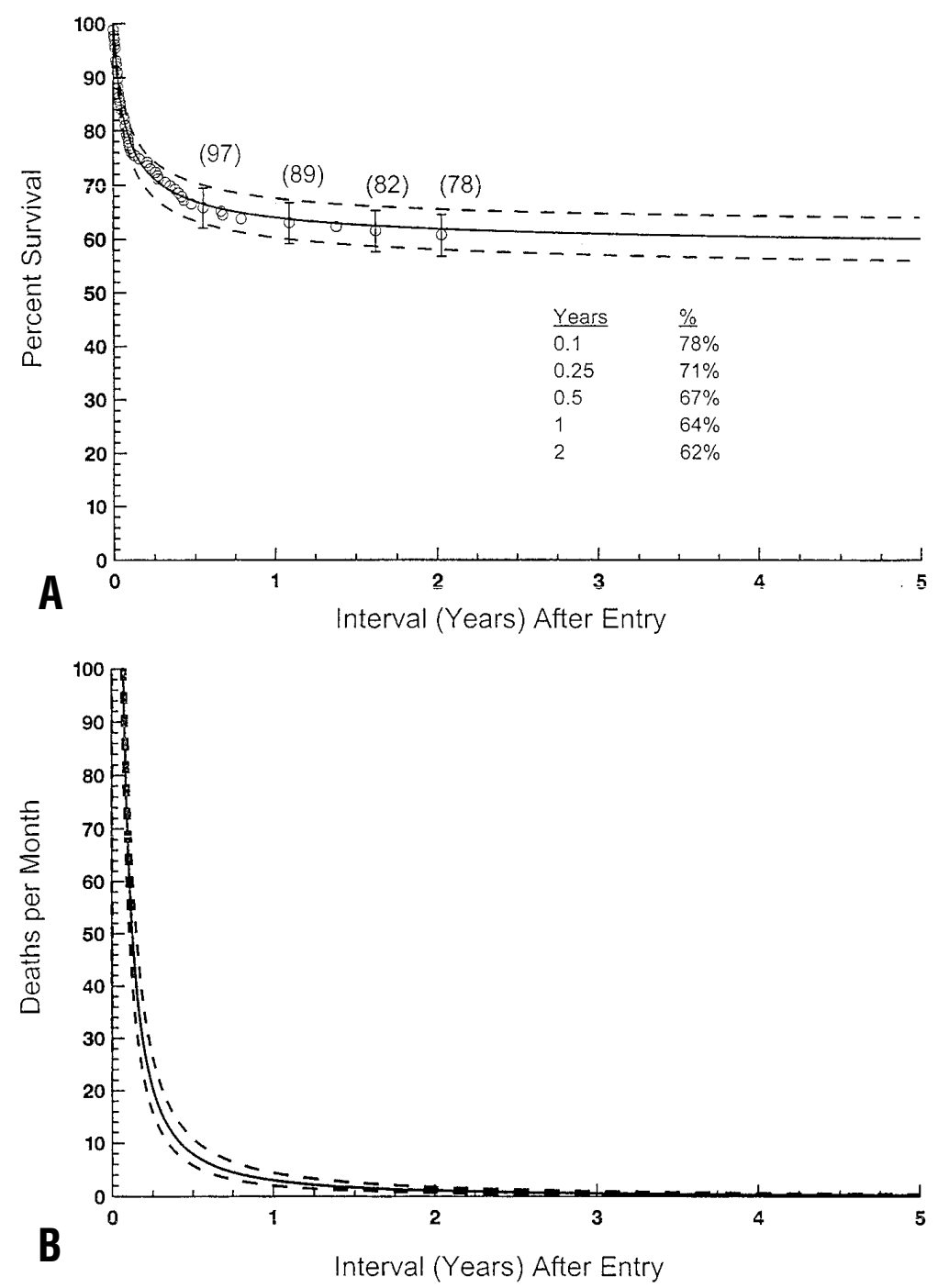

Fig 8. Survival after entry for patients who had an initial Norwood procedure $(n=179)$. The circles represent the Kaplan-Meier estimate for survival at each death, the solid lines represent the parametric determination of continuous point estimates, and the dashed lines enclose the $70 \%$ confidence interval. A, Percent survival; B, hazard function.

for these patients of $19 \% \pm 15 \%$. Likewise, 30 of the 179 patients (17\%) who had an initial Norwood procedure would have had better predicted survival at 5 years with a biventricular repair, with a mean increase in 5 -year survival of $15 \% \pm 11 \%$.

\section{Discussion}

Critical aortic stenosis has long been recognized by morphologists and practitioners as a cause of death in early infancy. As early as 1910, Carrel $^{5}$ and Jeger 6 independently attempted experimentally to place conduits between the left ventricular apex and the descending thoracic aorta. In 1955, a direct surgical approach to the aortic valve with the use of transventricular dilation was accomplished by Marquis and Logan, ${ }^{7}$ followed by Downey $^{8}$ in 1956. In 1956, the first open surgical valvotomy with surface cooling and inflow occlusion was performed. ${ }^{9-11}$ In 1958, the first report of open valvotomy with cardiopulmonary bypass was presented by Spencer, Neill, and Bahnson. ${ }^{12}$ These operations remained the only therapeutic options until 1983, when Lababidi ${ }^{13}$ reported the use of aortic balloon valvotomy, followed in 1984 by Lababidi, Wu, and Walls ${ }^{14}$ reporting on the use of this technique in 23 patients, including neonates. Numerous authors have since reported success with balloon valvotomy. ${ }^{15-25}$ 


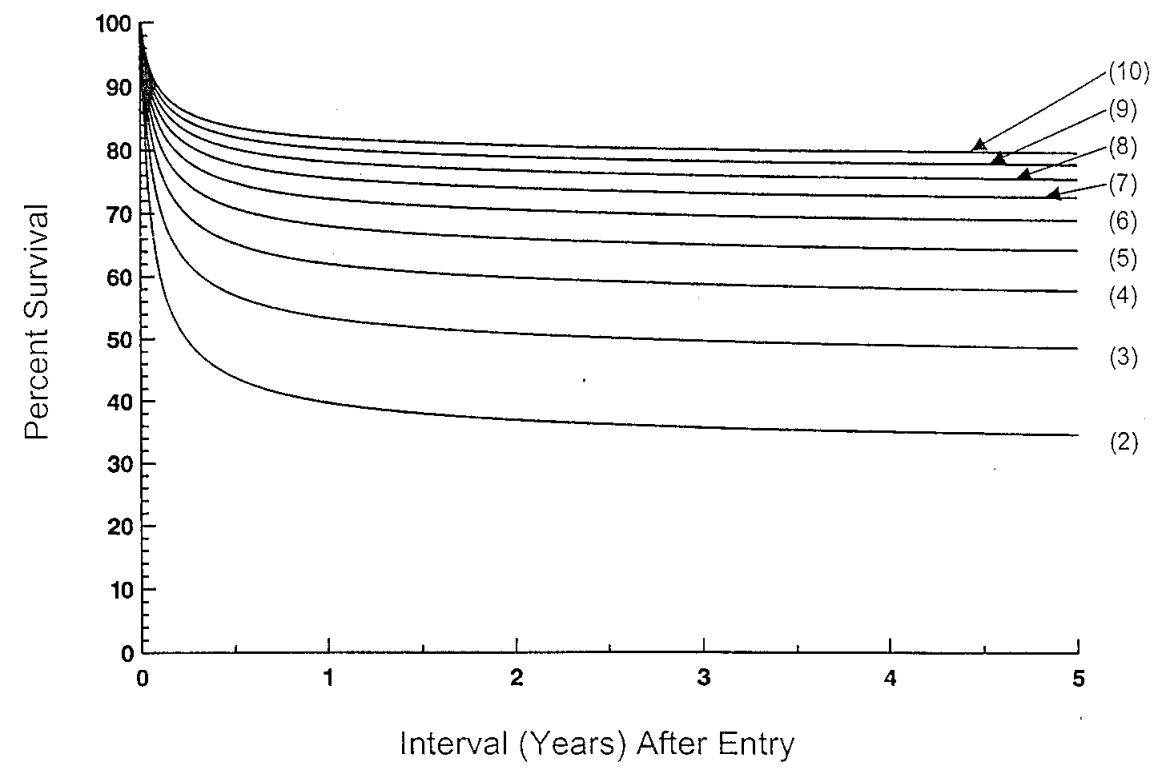

Fig 9. Risk-adjusted percent survival after entry predicted for a patient who had an initial Norwood procedure $(\mathrm{n}=179)$, stratified by the diameter of the ascending aorta above the sinotubular junction as measured on the initial echocardiogram. Moderate or severe tricuspid regurgitation was set as absent. Lines represent the parametric determination of continuous point estimates of survival.

Table V. Incremental risk factors for time-related death for patients who had an initial Norwood procedure

\begin{tabular}{lcc}
\hline \multicolumn{1}{c}{ Variable } & Parameter estimate* $(S E)$ & P value \\
\hline Lower diameter of the ascending aorta $\dagger$ & $0.952(0.397)$ & .017 \\
Presence of moderate or severe tricuspid regurgitation & $0.862(0.434)$ & .047 \\
\hline
\end{tabular}

$S E$, Standard error.

*For a single early hazard phase; adjusted for missing information for ascending aorta diameter.

$\dagger$ Entered after logarithmic transformation.

In the early 1980 s, Norwood and colleagues ${ }^{26-29}$ reported successful operations for the management of hypoplastic left heart syndrome. As outcomes with both surgical and balloon valvotomy remained marginal, and as the morphologic variability in the left-sided cardiac structures in patients with critical left ventricular outflow tract obstruction became more evident, the idea of abandoning a biventricular repair in favor of a single-ventricle palliation became attractive, but was again associated with significant mortality. In 1986, Bailey and associates $^{30}$ reported on successful orthotopic cardiac transplantation as a management strategy for neonates with hypoplastic left heart syndrome. This was a strategy that could easily be applied to neonates with critical aortic stenosis and other left-sided cardiac abnormalities. In 1987, Yasui and coworkers ${ }^{31}$ reported successful correction of critical aortic stenosis, interrupted aortic arch, and ventricular septal defect in 2 neonates. They used yet another operative approach that achieved a biventricular repair by Damus-Kaye-Stansel anastomosis between the ascending aorta and main pulmonary artery, with a Rastelli-type intracardiac tunnel and an extracardiac right ventricle-distal pulmonary artery conduit. Their approach abandoned the aortic valve and could be used if a ventricular septal defect was present.

In the early 1990s, McKay and colleagues ${ }^{32}$ examined the morphology of the ventriculoarterial junction in critical aortic stenosis in 21 patients at autopsy. These authors found diffuse and complex abnormalities that would suggest ongoing hemodynamic difficulties even in those patients who survived infancy. These authors suggested that early aortic root replacement with a pulmonary autograft might be the best way of achieving a biventricular correction. There have since been sporadic case reports of the pulmonary autograft, or Ross/Konno approach, performed in early infancy. ${ }^{33-35}$ Thus, by the early 1990s at least 6 different options were available to neonates with critical aortic stenosis, none of which met with universal success. Reasons for lack of success were difficult to quantify. 


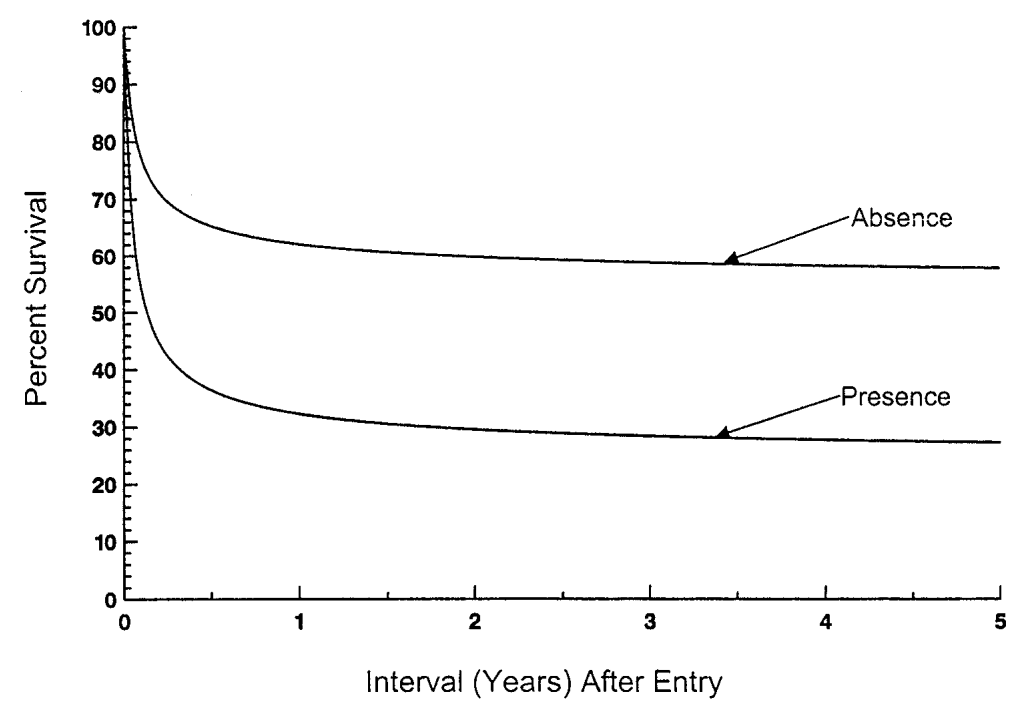

Fig 10. Risk-adjusted percent survival after entry predicted for a patient who had an initial Norwood procedure ( $n=179$ ), stratified by the presence or absence of moderate or severe tricuspid regurgitation as noted on the initial echocardiogram. The diameter of the ascending aorta above the sinotubular junction was set at $4 \mathrm{~mm}$. Lines represent the parametric determination of continuous point estimates of survival.

Table VI. Independent factors predictive of percent survival benefit at 5 years after entry for Norwood procedure versus biventricular repair*

\begin{tabular}{lcc}
\hline \multicolumn{1}{c}{ Variable } & Parameter estimate (SE) & P value \\
\hline Intercept & $-86.47(6.36)$ & \\
Higher grade of endocardial fibroelastosis & $12.14(0.96)$ & $<.001$ \\
Lower z-score of aortic valve at the level of the sinuses of Valsalva & $-6.20(0.25)$ & $<.001$ \\
Younger age at entry (d) $\dagger$ & $30.55(1.79)$ & $<.001$ \\
Larger ascending aorta diameter (mm) $\ddagger$ & $23.33(2.24)$ & $<.001$ \\
Absence of moderate or severe tricuspid regurgitation & $-28.30(2.60)$ & $<.001$ \\
Lower z-score of the LV length & $-0.70(0.22)$ & .02 \\
\hline
\end{tabular}

$S E$, Standard error.

*Adjusted for missing values for all variables; model $R^{2}=0.888$; root mean square error $=9.858$.

$\dagger$ Inverse of (age at entry +1 ) transformation.

$\ddagger$ Logarithmic transformation.

Prompted by therapeutic results that remained disappointing, investigators in the 1980s began matching hemodynamic and other parameters against outcomes in patients with critical aortic stenosis in an attempt to identify risk factors. Gundry and Behrendt, ${ }^{36}$ in a review of 24 patients undergoing aortic valvotomy in the first 6 months of life, found that a low ejection fraction, high left ventricular end-diastolic pressure, and presence of endocardial fibroelastosis were all predictive of poor outcome. Hammon and associates ${ }^{37}$ examined a group of 19 patients undergoing aortic valvotomy in the first 6 months of life and found that only elevated mean pulmonary artery pressure and low left ventricular end-diastolic volume were predictive of poor outcome; left ventricular peak systolic pressure, left ventricular end-diastolic pressure, systolic aortic valve gradient, left ventricular ejection fraction, and age at operation were not predictive.
Rhodes and associates ${ }^{38}$ examined a group of 65 patients with critical aortic stenosis after they had undergone a biventricular repair. The anatomic variables examined by these authors included the following: body surface area, indexed left ventricular enddiastolic volume, indexed left ventricular end-systolic volume, indexed left ventricular mass, indexed aortic anulus, indexed aortic root, indexed aortic arch, indexed aortic isthmus, indexed left ventricular long axis, relative left ventricular long axis, indexed mitral valve area, relative mitral valve area, Doppler gradients, and ejection fractions. These authors found that the best predictive equation for survival included body surface area (BSA), aortic root dimension indexed to body surface area $\left(\mathrm{ROOT}_{\mathrm{I}}\right)$, the ratio of the long-axis dimension of the left ventricle to the long-axis dimension of the heart (LAR), and the indexed mitral valve 
Table VII. Previous studies of risk factors for mortality in neonates with critical left ventricular outflow obstruction, small left ventricles, or both

\begin{tabular}{|c|c|c|c|c|}
\hline Study & No. of patients & Type of patients & Significant risk factors for mortality & Comments \\
\hline $\begin{array}{l}\text { Rhodes et al } \\
\text { (1991) }\end{array}$ & 65 & $\begin{array}{l}\text { Neonates and infants, } \\
\text { critical aortic stenosis }\end{array}$ & $\begin{array}{l}\text { BSA, indexed aortic root, ratio of LV to } \\
\text { heart length, indexed mitral valve area }\end{array}$ & $\begin{array}{l}\text { Patients preselected for biventricular } \\
\text { repair, all had valvotomy }\end{array}$ \\
\hline $\begin{array}{l}\text { Parsons et al } \\
\text { (1991) }\end{array}$ & 25 & $\begin{array}{l}<3 \text { months, } \\
\text { aortic valvotomy }\end{array}$ & $\begin{array}{l}\text { Age, mitral valve diameter, LV } \\
\text { end-diastolic dimension, left atrial } \\
\text { dimension and cross-sectional area, } \\
\text { LV end-diastolic volume }\end{array}$ & $\begin{array}{l}\mathrm{LV} \text { cross-sectional area }<2 \mathrm{~cm}^{2} \text { is a } \\
\text { risk factor for perioperative death }\end{array}$ \\
\hline $\begin{array}{l}\text { Kovalchin et al } \\
\text { (1997) }\end{array}$ & 28 & $\begin{array}{l}\text { Neonates, critical } \\
\text { aortic stenosis }\end{array}$ & $\begin{array}{l}\text { Indexed aortic anulus, aortic root, } \\
\text { ascending aorta, LV long-axis } \\
\text { length, direction flow ascending and } \\
\text { transverse aorta }\end{array}$ & $\begin{array}{l}\text { Echocardiographic determination of } \\
\text { morphology and direction of aortic }\end{array}$ \\
\hline $\begin{array}{l}\text { Tani et al } \\
\text { (1999) }\end{array}$ & 20 & $\begin{array}{l}\text { Neonates, aortic } \\
\text { arch obstruction, } \\
\text { coarctation, no critical } \\
\text { aortic stenosis }\end{array}$ & & $\begin{array}{l}\text { Retrospective review of } 20 \text { neonates } \\
\text { with a Rhodes score that would } \\
\text { have precluded biventricular } \\
\text { repair-undergoing successful } \\
\text { biventricular repair }\end{array}$ \\
\hline
\end{tabular}

$B S A$, Body surface area; $L V$, left ventricular.

area $\left(\mathrm{MVA}_{\mathrm{I}}\right)$. The equation for the discriminating score for survival was as follows: Score $=14.0(\mathrm{BSA})+$ $0.943\left(\right.$ ROOT $\left._{\mathrm{I}}\right)+4.78(\mathrm{LAR})+0.157\left(\mathrm{MVA}_{\mathrm{I}}\right)-12.3$, with a discriminating score of less than -0.35 predictive of death after a 2-ventricle repair. The equation was found to have a predictive value of $88 \%$ to $91 \%$ when applied to their own patient group. For the next several years, several investigators attempted to assess the performance of the Rhodes score in predicting survival in other patient groups. ${ }^{39-41}$ The results of these efforts are summarized in Table VII.

Other authors have examined whether biventricular repair can be accomplished in ductus-dependent neonates with multiple levels of left ventricular outflow tract obstruction and hypoplastic but morphologically normal left ventricles. ${ }^{42,43}$ Both series reported a high incidence of reoperation even if a successful biventricular repair could be accomplished. Thus, there exists no unanimity of opinion regarding what combination of left-sided structures will be adequate to perform a biventricular correction and how that adequacy can be accurately assessed before embarking on 1 of 6 therapeutic pathways. Indeed, one group of authors has even advocated the continued use of transventricular dilation for critical aortic stenosis in neonates, thus further clouding an already murky picture. ${ }^{44}$

Each of the previous studies involved small numbers of patients, a fact that helps to account for the variability between studies as to which demographic, hemodynamic, and morphometric factors were important in predicting outcomes after 2-ventricle versus 1-ventricle repair for patients with critical aortic stenosis. The present study involves a patient group that is greater in number than the total number for all other studies com- bined and examines as independent variables all of the parameters investigated by all of the other authors. Thus, innumerable independent variables were examined for each of the 320 patients. The large patient cohort enabled multiple logistic regression which determined features that discriminated between patients selected for biventricular repair versus Norwood pathways. Parametric modeling of survival and hazard of time-related death was performed separately for the biventricular and Norwood patients, and independent risk factors for timerelated death were determined from these 2 hazard models. A prediction of survival at 5 years could be calculated for all patients. Indeed, for each patient, predicted survival for the biventricular repair versus the Norwood pathway was compared, with the difference representing the predicted survival benefit. Multiple linear regression analysis was then performed to identify independent factors associated with the survival benefit. The final result was a multiple linear regression equation that predicted both the magnitude and the direction of the survival benefit for the optimal pathway. The regression equation can be solved for characteristics of an individual patient to give the predicted 5-year survival benefit of Norwood versus biventricular repair as follows:

Survival benefit $=$ Intercept + b1 (age at entry)

$+\mathrm{b} 2$ (z-score of aortic valve at the sinuses) $+\mathrm{b} 3$

(grade of EFE) $+\mathrm{b} 4$ (ascending aorta diameter) $+\mathrm{b} 5$ (presence of moderate or severe tricuspid regurgitation) $+\mathrm{b} 6$ (z-score of the left ventricular length)

with the appropriate transformations and parameter estimates as given in Table VI. The $70 \%$ confidence interval can be calculated by adding and subtracting the root mean square error from the predicted survival ben- 


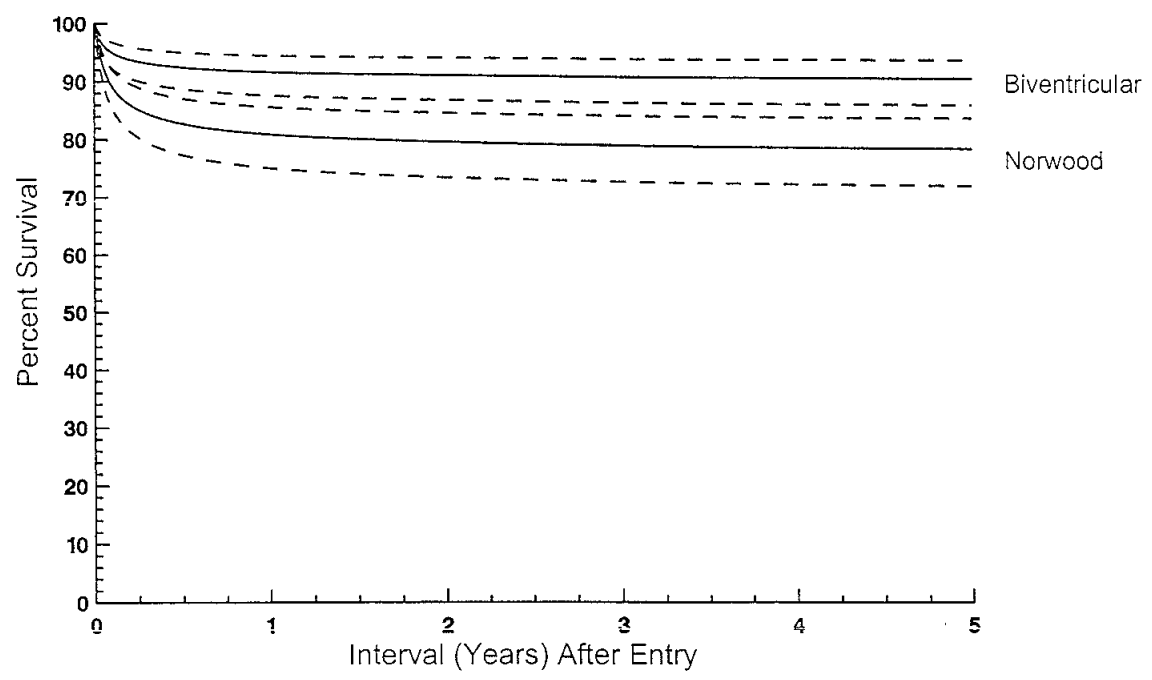

Fig 11. Risk-adjusted percent survival after entry predicted for both an initial intended biventricular repair and a Norwood procedure pathway for a study patient who had an initial Norwood procedure and survived. The patient's characteristics were as follows: age at entry, 8 days, z-score of the aortic valve at the level of the sinuses of Valsalva, $-3.2(7.6 \mathrm{~mm})$; grade of endocardial fibroelastosis, 0 or absent; diameter of the ascending aorta, $9.4 \mathrm{~mm}$; moderate or severe tricuspid regurgitation, absent; and z-score of the left ventricular length, -2.2. The solid lines represent the parametric determination of continuous point estimates of survival, with the dashed lines enclosing the $70 \%$ confidence interval. The predicted survival at 5 years after entry for this patient would be $78 \%$ for a Norwood procedure pathway and $91 \%$ for a biventricular repair pathway. The predicted survival benefit from the multiple linear regression equation would be $+9.7 \%$ in favor of biventricular repair pathway ( $70 \%$ confidence interval, $-0.1 \%$ to $+19.6 \%$ ).

efit. The result gives the predicted difference in percent survival for Norwood minus biventricular repair. A positive number would therefore favor a Norwood procedure and a negative number would favor a biventricular repair, with the magnitude of the number representing the predicted difference in percent survival or the survival benefit for the optimal pathway.

An example of how the multiple linear regression equation can be used to predict optimal pathway and survival benefit is demonstrated for individual patients in Figs 11 and 12.

From this study, 4 conclusions might be drawn. First, mortality is high for critical left ventricular outflow tract obstruction in neonates. Second, survival may be improved by more appropriate selection of repair pathways. Third, risk factors for mortality differ for Norwood versus biventricular repair pathways. Finally, the pathways predicting survival benefit from Norwood versus biventricular repair relate to the adequacy of left-sided structures.

We may also make several inferences from our findings. First, the use of a multivariable equation from these data would improve patient selection for Norwood or biventricular repair and overall survival in neonates with critical left ventricular outflow obstruction. Second, without the use of the equation, there is a significant error rate for each pathway, with $50 \%$ of the biventricular repair patients having better predicted survival with a Norwood approach and $20 \%$ of the Norwood patients having better predicted survival with biventricular repair. Third, the present study is limited in that we cannot yet examine late problems that might be anticipated to occur in both groups of patients. Patients undergoing biventricular repair experience ongoing problems with the left ventricular outflow tract and future problems related to the mitral valve and aortic arch. Likewise, the singleventricle pathway patients may yet experience problems associated with aging and single-ventricle physiology. Fourth, the role of the Ross procedure in patients for whom a biventricular repair pathway is undertaken could not be determined by this study. Last, the role of primary cardiac transplantation could not be evaluated. There may be a selected group of patients on both the biventricular repair and the Norwood pathways for whom survival with either approach would be so poor that primary cardiac transplantation may offer the only viable approach. It is likely that patients who have a very small ascending aorta may fall into this category.

Along with members of the CHSS, we strongly encourage the prospective use of this multiple variable equation in determining management strategies with neonates with critical aortic stenosis. The multiple 


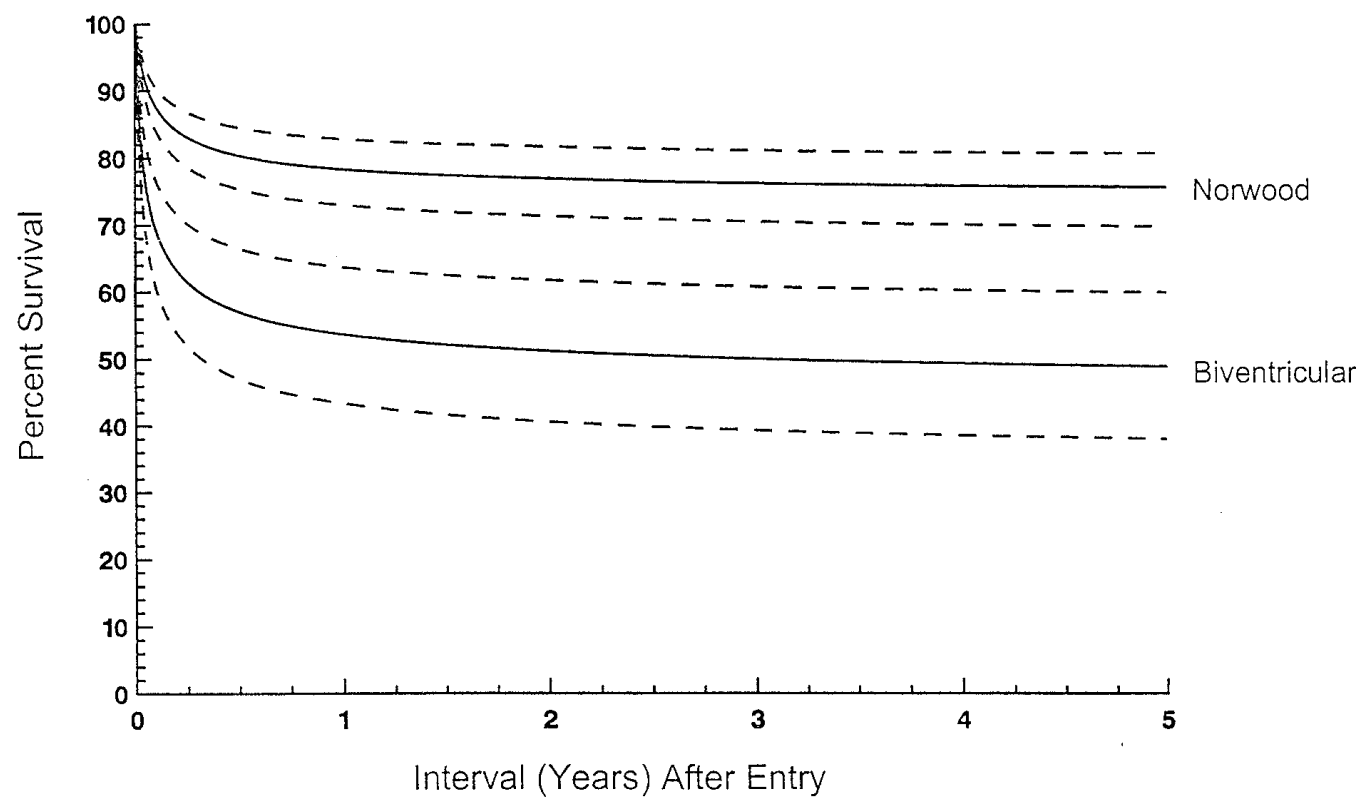

Fig 12. Risk-adjusted percent survival after entry predicted for both an initial intended biventricular repair and a Norwood procedure pathway for a study patient who had an initial aortic valvotomy and died. The patient's characteristics were as follows: age at entry, $<1$ day, z-score of the aortic valve at the level of the sinuses of Valsalva, $-3.5(7.3 \mathrm{~mm})$; grade of endocardial fibroelastosis, 1 or papillary muscles only; diameter of the ascending aorta, $8.1 \mathrm{~mm}$; moderate or severe tricuspid regurgitation, absent; and z-score of the left ventricular length, -1.0 . The solid lines represent the parametric determination of continuous point estimates of survival, with the dashed lines enclosing the $70 \%$ confidence interval. The predicted survival at 5 years after entry for this patient would be $76 \%$ for a Norwood procedure pathway and $49 \%$ for a biventricular repair pathway. The predicted survival benefit at 5 years derived from the multiple linear regression equation would be $+27.3 \%$ in favor of Norwood procedure pathway ( $70 \%$ confidence interval, $+17.4 \%$ to $+37.2 \%$ ).

variable equation will be posted on the Web site of the CHSS, along with a built-in calculator. The CHSS Web site can be accessed at www.chssdc.org.

We acknowledge the assistance of the personnel at the Congenital Heart Surgeons Society Data Center, especially Geraldine Cullen-Dean and Jay Joseph, in the analysis of these data and preparation of the manuscript. We also acknowledge the advice and assistance of Jeffrey $\mathrm{F}$. Smallhorn, MD, in echocardiographic interpretation.

\section{REFERENCES}

1. Jacobs ML, Blackstone EH, Bailey LL. Surgery for congenital heart disease: intermediate survival in neonates with aortic atresia-a multi-institutional study. J Thorac Cardiovasc Surg 1998;116:417-31.

2. Jonas RA, Quaegebeur JM, Kirklin JW, Blackstone EH, Daicoff G. Outcomes in patients with interrupted aortic arch and ventricular septal defect: a multi-institutional study. Congenital Heart Surgeons Society. J Thorac Cardiovasc Surg 1994;107:1099-113.

3. Daubeny PEF, Blackstone EH, Weintraub RG, Slavik Z, Scanlon J, Weber SA. Relationship of the dimension of cardiac structures to body size: an echocardiographic study in normal infants and children. Cardiol Young 1999;9:402-10.

4. Blackstone EH, Naftel DC, Turner ME Jr. The decomposition of time-varying hazard into phases, each incorporating a separate stream of concomitant information. J Am Stat Assoc 1986;81:615-24.

5. Carrel A. On the experimental surgery of the thoracic aorta and the heart. Ann Surg 1910;52:83.

6. Jeger E. Die Chirurgie der Blutgafassen und des Herzens. Berlin: August Hirchwald; 1913.

7. Marquis RM, Logan A. Congenital aortic stenosis and its surgical treatment. Br Heart J 1955;17:373-90.

8. Downing DF. Congenital aortic stenosis: clinical aspects and surgical treatment. Circulation 1956;14:188-99.

9. Lewis FJ, Shumway NE, Niazi SA, Benjamin RB. Aortic valvulotomy under direct vision during hypothermia. J Thorac Surg 1956;32:481-99.

10. Swan H, Wilkinson RH, Blount SG Jr. Visual repair of congenital aortic stenosis during hypothermia. J Thorac Surg 1958; 35:139-53.

11. Swan H, Kortz AB. Direct vision trans-aortic approach to the aortic valve during hypothermia: experimental observations and report of a successful clinical case. Ann Surg 1956;144:205-14.

12. Spencer FC, Neill CA, Bahnson HT. The treatment of congenital aortic stenosis with valvotomy during cardiopulmonary bypass. Surgery 1958;44:109-24.

13. Lababidi Z. Aortic balloon valvuloplasty. Am Heart J 1983;106 (4 Pt 1):751-2.

14. Lababidi Z, Wu JR, Walls JT. Percutaneous balloon aortic valvuloplasty: results in 23 patients. Am J Cardiol 1984;53:194-7.

15. Kasten-Sportes C, Piechaud J-F, Sidi D, Kachaner J. 
Percutaneous balloon valvuloplasty in neonates with critical aortic stenosis. J Am Coll Cardiol 1989;13:1101-5.

16. Beekman R, Rocchini A, Andes A. Balloon valvuloplasty for critical aortic stenosis in the newborn: influence of new catheter technology. J Am Coll Cardiol 1991;17:1172-6.

17. Fischer DR, Ettedgui JA, Park SC, Siewers RD, del Nido PJ. Carotid artery approach for balloon dilatation of aortic valve stenosis in the neonate: a preliminary report. J Am Coll Cardiol 1990; $15: 1633-6$

18. Neish SR, O'Laughlin MP, Nihill MR, Ott DA, Cooley DA. Intraoperative balloon valvuloplasty for critical aortic valvular stenosis in neonates. Am J Cardiol 1991;68:807-10.

19. Bu'Lock F, Stephen H, Martin R. Balloon dilatation (valvuloplasty) as first time treatment for severe stenosis of the aortic valve in early infancy: medium term results and determinants of survival. Br Heart J 1993;70:546-53.

20. Mosca RS, Iannettoni MD, Schwartz SM, Ludomirsky A, Beekman RH, Lloyd T, et al. Critical aortic stenosis in the neonate. J Thorac Cardiovasc Surg 1995;109:147-54.

21. Moore P, Egito E, Mowrey H, Perry SB, Lock JE, Keane JF. Midterm results of balloon dilatation of congenital aortic stenosis: predictors of success. J Am Coll Cardiol 1996;27:1257-63.

22. Justo RN, McCrindle BW, Benson LN, Williams WG, Freedom RM, Smallhorn JF. Aortic valve regurgitation after surgical versus percutaneous balloon valvotomy for congenital aortic valve stenosis. Am J Cardiol 1996;77:1332-8.

23. McCrindle B. Independent predictors of immediate results of percutaneous balloon aortic valvotomy in childhood. Am J Cardiol 1996;77:286-93.

24. Galal O, Rao PS, Al-Fadley F, Wilson AD. Follow-up results of balloon aortic valvuloplasty in children with special reference to causes of late aortic insufficiency. Am Heart J 1997;133:418-27.

25. Maeno Y, Akagi T, Hashino K, Ishii M, Sugimura T, Takagi J, et al. Carotid artery approach to balloon aortic valvuloplasty in infants with critical aortic valve stenosis. Pediatr Cardiol 1997;18:288-91.

26. Norwood WI, Stellin GJ. Aortic atresia with interrupted aortic arch. J Thorac Cardiovasc Surg 1981;81:239-44.

27. Norwood WI, Lang P, Hansen D. Physiologic repair of aortic atresia-hypoplastic left heart syndrome. $N$ Engl J Med 1983;308:23-6

28. Norwood WI, Lang P, Castaneda AR, Campbell DN. Experience with operations for hypoplastic left heart syndrome. J Thorac Cardiovasc Surg 1981;82:511-9.

29. Norwood WI, Kirklin JK, Sanders SP. Hypoplastic left heart syndrome: experience with palliative surgery. Am J Cardiol 1980;45:87-91.

30. Bailey LL, Nelsen-Cannarella SL, Doroshow RW, Jacobson JG, Mastin RD, Allard MW, et al. Cardiac allotransplantation in newborns as therapy for hypoplastic left heart syndrome. $\mathrm{N}$ Engl $\mathrm{J}$ Med 1986;315:949-51.

31. Yasui H, Kado H, Nakano E, Yonenaga K, Mitani A, Tomita Y, et al. Primary repair of interrupted aortic arch and severe aortic stenosis in neonates. J Thorac Cardiovasc Surg 1987;93:539-45.

32. McKay R, Smith A, Leung MP, Arnold R, Anderson RH. Morphology of the ventriculoaortic junction in critical aortic stenosis. J Thorac Cardiovasc Surg 1992;104:434-42.

33. Calhoon J, Bolton J. Ross/Konno procedure for critical aortic stenosis in infancy. Ann Thorac Surg 1995;60:S597-9.

34. Sudow G, Solymar L, Berggren H, Eriksson B, Holmgren D, Gilljam T. Aortic valve replacement with a pulmonary autograft in infants with critical aortic stenosis. J Thorac Cardiovasc Surg 1996;112:433-6.
35. Reddy VM, Rajasinghe HA, Teitel DF, Haas GS, Hanley FL. Aortoventriculoplasty with the pulmonary autograft: the "RossKonno" procedure. J Thorac Cardiovasc Surg 1996;111:158-67.

36. Gundry S, Behrendt D. Prognostic factors in valvotomy for critical aortic stenosis in infancy. J Thorac Cardiovasc Surg 1986;92:747-54

37. Hammon J, Lupinetti FM, Maples MD, Merrill WM, Frist WH, Graham TP, et al. Predictors of operative mortality in critical valvular aortic stenosis presenting in infancy. Ann Thorac Surg 1988;45:537-40

38. Rhodes LA, Colan SD, Perry SB, Jonas RA, Sanders SP. Predictors of survival in neonates with critical aortic stenosis. Circulation 1991;84:2325-35.

39. Parsons MK, Moreau GA, Graham TP, Johns JA, Boucek RJ. Echocardiographic estimation of critical left ventricular size in infants with isolated aortic valve stenosis. J Am Coll Cardiol 1991;18:1049-55.

40. Kovalchin J, Brook M, Silverman N. Growth of the hypoplastic left ventricle? Pediatr Cardiol 1997;18:451-2.

41. Tani LY, Minich LL, Pagotto LT, Shaddy RE, McGough EC, Hawkins JA. Left heart hypoplasia and neonatal aortic arch obstruction: Is the Rhodes left ventricular adequacy score applicable? J Thorac Cardiovasc Surg 1999;118:81-6.

42. Serraf A, Piot JD, Bonnet N, Lacour-Gayet F, Touchot A, Bruniaux J, et al. Biventricular repair approach in ducto-dependent neonates with hypoplastic but morphologically normal left ventricle. J Am Coll Cardiol 1999;33:827-34.

43. Tchervenkov CI, Tahta SA, Jutras LC, Beland MJ. Biventricular repair in neonates with hypoplastic left heart complex. Ann Thorac Surg 1998;66:1350-7.

44. Friberg LG, Mellgren GW, Mellander M, Solymar L. Transventricular dilatation for critical aortic stenosis in neonates. J Pediatr Surg 1992;27:1097-9.

\section{Discussion}

Dr Frank L. Hanley (San Francisco, Calif). This project is an impressive undertaking. I congratulate the authors for their work.

This study contains a great deal of information, so it is particularly important to distill this information down to the essentials. First, it is important to understand that left ventricular outflow tract obstruction in the neonate is a morphologic and physiologic spectrum. The surgeon, however, must make a dichotomous decision with respect to treatment: 2ventricle repair or Norwood. The study population comprises 2 large groups, those treated with a Norwood procedure and those treated with so-called 2-ventricular repair, which, in essence, is aortic valvotomy; 111 of 116 patients had aortic valvotomy in that second group.

Using the statistical methods described, the study examines outcomes and incremental risk factors for time-related death for each group, Norwood and aortic valvotomy. The eventual model, as represented by the multivariable hazard function equation, can then be solved twice for each individual, as shown in several examples, once for the Norwood and once for the 2-ventricle, or aortic valvotomy, repair. The 2 values can then be compared to determine the optimal treatment for each individual patient.

Specifically looking at the patients who underwent aortic valvotomy, the analysis shows that death is increasingly more 
likely in patients with smaller aortic valves and in the presence of endocardial fibroelastosis. This makes perfect sense. Aortic valvotomy does not address either of these morphologic issues, so it is not surprising that attempting an aortic valvotomy in the face of increasingly small aortic valves and increasing endocardial fibroelastosis will be completely ineffective. It would not be too dramatic to say that aortic valvotomy in this setting is a completely irrational treatment option.

When the predicted mortality for a given patient becomes higher with aortic valvotomy than with a Norwood procedure, this study suggests that the Norwood operation should be the treatment of choice. This is somewhat logical and makes a certain amount of intuitive sense until one includes the reality that survival for the average Norwood operation is $62 \%$ at 2 years. It is difficult to be enthusiastic about choosing an alternative operation for any individual patient when that alternative offers only a $62 \%$ survival at 2 years.

As such, the analysis could not be a better advertisement for recommending the pulmonary autograft as the procedure of choice for patients with many forms of critical neonatal left ventricular outflow tract obstruction. The Ross procedure normalizes the left ventricular outflow tract dimensions and hemodynamics and allows easy access to the left ventricular myocardium for resection of endocardial fibroelastosis. This not only gets rid of the endocardial fibroelastosis but actually lengthens the long dimension of the left ventricle, another risk factor identified in this study. Therefore, it directly addresses the two most important morphologic risk factors for death with an attempted 2-ventricle repair.

According to the analysis represented by the models in this study, for an individual patient with an aortic valve z-value of zero and absence of endocardial fibroelastosis, the 5-year survival is greater than $95 \%$. Unfortunately, not many neonates with critical left ventricular outflow obstruction have these favorable morphologic characteristics. The Ross, or RossKonno, if necessary, or Ross-Konno with endocardial fibroelastosis resection can reassign many of the high-risk patients with critical left ventricular outflow tract obstruction into patients with normal aortic valve diameter and no endocardial fibroelastosis. The models in this study could then predict a 95\% 5-year survival. My own experience with the Ross operation in this very same setting would substantiate that kind of 5 -year outcome. Such an outcome is clearly superior to valvotomy and is also clearly superior to the alternative, the Norwood operation, with a $60 \%$ 2-year survival.

I have 2 specific questions; both relate somewhat more to the manuscript than to the presentation. The manuscript mentions that patients were entered into the study up until February 2000. The manuscript also mentions that follow-up was completed in September 1999. Now, either that is a typographical error or the patients entered after September 1999 were somehow treated in a different manner with less or different or no follow-up. This issue should be clarified.

The second point relates to the method, with respect to the analysis of the endocardial fibroelastosis. The study of the autopsy series shows relatively poor correlation between the echocardiographic diagnosis of endocardial fibroelastosis, which was used in the analysis, and a few patients in whom autopsy evidence of endocardial fibroelastosis was shown. The 2 methods agreed on the exact degree of endocardial fibroelastosis in only 8 of 23 patients tested.

It seems that the echocardiogram underestimated the spectrum of endocardial fibroelastosis; in other words, it underestimated both the absent endocardial fibroelastosis and the very severe endocardial fibroelastosis. I would be interested in your comments on this lack of correlation and how you think the echocardiographic diagnosis narrowing the spectrum of endocardial fibroelastosis may have implications for your multivariable analysis.

Dr Lofland. Thank you for your kind comments, Dr Hanley. We share the observations you have expressed about the utility of the Ross procedure or the pulmonary autograft. This study was truly a collaborative effort in the finest sense of the word, and we are still actively enrolling patients in the study, which helps to explain a little bit of the discrepancy in follow-up terminology.

Regarding the grading of endocardial fibroelastosis, we attempted in this study to examine every variable that every other author has ever proposed as a risk factor for patients with critical aortic stenosis or critical left ventricular outflow tract obstruction. Granted there will be discrepancy between echocardiographic grading of endocardial fibroelastosis and grading at autopsy. We went with echocardiographic grading because that is the grading method that will be used in clinical decision-making for these patients.

Appendix A. Morphologic and functional characteristics measured and calculated from the independent blinded review of the initial echocardiogram reading

\begin{tabular}{lll}
\hline \multicolumn{1}{c}{ Variable name } & Echo view & \multicolumn{1}{c}{ Comment } \\
\hline Right atrium, tricuspid valve & & \\
Right atrial area $\left(\mathrm{cm}^{2}\right)$ & SC & Traced endocardial surface \\
Size of ASD or PFO $(\mathrm{mm})$ & SC & \\
Flow characteristics across ASD or PFO & SC & From color flow Doppler \\
Gradient across ASD or PFO $(\mathrm{mm} \mathrm{Hg})$ & SC & From pulsed Doppler \\
Tricuspid valve AP diameter $(\mathrm{mm})$ & PSLA & Measured between hinge points at anulus \\
Tricuspid valve lateral diameter $(\mathrm{mm})$ & AP4C & Measured between hinge points at anulus \\
Grade of tricuspid regurgitation & AP4C, PSSA & From color flow Doppler \\
Tricuspid regurgitation gradient $(\mathrm{mm} \mathrm{Hg})$ & AP4C & From pulsed and continuous wave Doppler \\
\hline
\end{tabular}


Appendix A. Cont'd

\begin{tabular}{|c|c|c|}
\hline Variable name & Echo view & Comment \\
\hline \multicolumn{3}{|l|}{ Ventricular septum } \\
\hline Presence and characteristics of VSD & All views & VSD number, size, location \\
\hline Gradient across VSD (mm Hg) & All views & From pulsed and continuous wave Doppler \\
\hline \multicolumn{3}{|l|}{ Left atrium, mitral valve } \\
\hline Left atrial area $(\mathrm{cm} 2)$ & $\mathrm{SC}$ & Traced from endocardial surface \\
\hline Mitral valve AP diameter (mm) & PSLA & Measured between hinge points at anulus \\
\hline Mitral valve lateral diameter (mm) & AP4C & Measured between hinge points at anulus \\
\hline Grade of mitral regurgitation & AP4C, PSLA & From color flow Doppler \\
\hline Mitral regurgitation jet width (mm) & $\mathrm{AP} 4 \mathrm{C}$ & Diameter of color flow Doppler jet at anulus \\
\hline Characteristics, gradient of mitral obstruction & AP4C, PSLA & $\begin{array}{l}\text { Level of obstruction (annular, subvalvular or supravalvular), } \\
\text { Doppler gradient }\end{array}$ \\
\hline Mitral valve structural anomalies & PSSA & $\begin{array}{l}\text { Parachute mitral valve, thickening and mobility of leaflets, papillary } \\
\text { muscle position }\end{array}$ \\
\hline \multicolumn{3}{|l|}{ Left ventricle } \\
\hline Long-axis endocardial length of LV (mm) & AP4C, diastole & Measured from mitral valve anulus level to endocardium of LV apex \\
\hline Long-axis epicardial length of LV (mm) & AP4C, diastole & Measured from mitral valve anulus level to epicardium of LV apex \\
\hline Long-axis endocardial of heart (mm) & AP4C, diastole & Measured from crux of heart to endocardium to apex \\
\hline Long-axis endocardial length of LV (mm) & AP4C, systole & $\begin{array}{l}\text { Measured from mitral valve anulus level to endocardium of LV } \\
\text { apex }\end{array}$ \\
\hline Short-axis LV endocardial area $(\mathrm{cm} 2)$ & PSSA, diastole & Traced from endocardial surface at midventricular level \\
\hline Short-axis LV epicardial area (cm2) & PSSA, diastole & Trace from epicardial surface at midventricular level \\
\hline Short-axis LV endocardial area $(\mathrm{cm} 2)$ & PSSA, systole & Traced from endocardial surface at midventricular level \\
\hline Presence/grade of endocardial fibroelastosis & All views & $\begin{array}{l}\text { Mild_-involves only papillary muscle area } \\
\text { Moderate_-papillary muscle and some part of LV endocardium } \\
\text { Severe_extensive endocardial involvement }\end{array}$ \\
\hline \multicolumn{3}{|l|}{ Subaortic region, aortic valve } \\
\hline Type of obstruction of subaortic region & All views & Fibromuscular ridge, tunnel, chordae, or other mechanism \\
\hline Smallest diameter of subaortic area (mm) & PSLA, systole & From endocardial surface \\
\hline Gradient across LV outflow tract (mm Hg) & AP5C, SSN & $\begin{array}{l}\text { From pulsed and continuous wave Doppler, peak instantaneous and } \\
\text { mean gradient }\end{array}$ \\
\hline Aortic valve characteristics & All views & Number of cusps, mobility, thickening \\
\hline Grade of aortic regurgitation & PSLA & From color Doppler \\
\hline Aortic regurgitation jet width $(\mathrm{mm})$ & PSLA & Diameter of color flow Doppler jet at anulus \\
\hline Aortic valve anulus (mm) & PSLA & Measured between hinge points at anulus \\
\hline Aortic root (sinus of Valsalva) diameter (mm) & PSLA & Measured at maximal dimension, inner surface \\
\hline Sinotubular junction diameter (mm) & PSLA & Measured at maximal dimension, inner surface \\
\hline \multicolumn{3}{|l|}{ Ascending aorta, aortic arch } \\
\hline Ascending aorta (mm) & PSLA & Measured at level above sinotubular junction \\
\hline Distal transverse aortic arch (mm) & SSN & Measured between LCC and LSCA \\
\hline Aortic isthmus (mm) & SSN & Measured distal to LSCA \\
\hline Descending aorta $(\mathrm{mm})$ & $\mathrm{SC}$ & Measured at level of diaphragm \\
\hline Flow characteristics at ascending aorta & SSN & $\begin{array}{l}\text { Predominant antegrade or retrograde flow from pulsed and color } \\
\text { flow Doppler }\end{array}$ \\
\hline Flow characteristics at transverse aortic arch & SSN & $\begin{array}{l}\text { Predominant antegrade or retrograde flow fromm pulsed and color } \\
\text { flow Doppler }\end{array}$ \\
\hline Aortic coarctation diameter (mm) & SSN & Narrowest dimension \\
\hline Ductus arteriosus characteristics & SSN & Size, flow characteristics, gradient \\
\hline \multicolumn{3}{|l|}{ Calculated values } \\
\hline \multicolumn{3}{|l|}{ Rhodes score } \\
\hline \multicolumn{3}{|l|}{ LV mass } \\
\hline \multicolumn{3}{|l|}{ LV long-axis ratio to heart } \\
\hline \multicolumn{3}{|c|}{ LV end-systolic and end-diastolic volumes } \\
\hline \multicolumn{3}{|c|}{ Ejection fraction calculated from diameters and volumes } \\
\hline \multicolumn{3}{|c|}{ Ratio of regurgitant jet width to anulus width } \\
\hline \multicolumn{3}{|l|}{ Mitral and tricuspid valve areas } \\
\hline Ratio of mitral valve area to sum of mitral and & $\mathrm{d}$ valve areas & \\
\hline
\end{tabular}

Many variables were also indexed to body surface area or converted to z-scores.

Echocardiogram views: AP4C, Apical 4-chamber; AP5C, apical 5-chamber; PSLA, parasternal long axis; PSSA, parasternal short axis; SC, subcostal; SSN, suprasternal notch. $A P$, Anteroposterior; $A S D$, atrial septal defect; $L L C$, left common carotid; $L S C A$, left subclavian artery; $L V$, left ventricle (ventricular); $P F O$, patent foramen ovale; $V S D$, ventricular septal defect. 